\title{
We all live in a planetary Ark (planetary Ark, planetary Ark....)
}

Hub Zwart

H. Zwart (2016) We all live in a planetary Ark (planetary Ark, planetary Ark....). In: Bovenkerk, Bernice; Keulartz, Jozef (eds.) Animal Ethics in the Age of Humans. Blurring boundaries in human-animal relationships. pp. 397-407. Dordrecht: Springer: The International Library of Environmental, Agricultural and Food Ethics. Volume 23

\begin{abstract}
The Biblical story of the Art (a floating, zoo-like device, constructed to survive climate turmoil and mass extinction) can be regarded as an archetypal image (in the terminology of Gaston Bachelard), capturing structural components of the human-animal relationship. Building on the contributions by Larson and Barr, Keulartz, Bovenkerk and Verweij, and Ramp and Bekoff, I will argue that, in the course of history, the Ark has evolved from a fictional (imaginary) icon into something increasingly real. The agricultural village of the Neolithic era already functioned as a sheltered enclave, a survival machine designed to allow a select number of humans and accompanying species to withstand environmental fluctuations and survival pressure. In the current situation, however, the Ark has developed into a Gestell of planetary dimensions. The concept of the anthropocene basically conveys the idea that we have entered a global symbolical Ark, conceptualised by Teilhard de Chardin as the noosphere (the world-wide web of intelligence and policies, technologies and engineering, research and regulations) and emerging against the backdrop of a necro(s)cene: an ambiance of mass extinction. Increasingly, prospects for survival of a disconcertingly large number of species depend on human behaviour and human decision: on our ability or failure to collectively address the daunting challenges of the present.
\end{abstract}




\section{We all live in a planetary Ark (planetary Ark, planetary Ark....)}

\section{Introduction}

The image of the Ark still functions as an archetypal marker in contemporary discourse on human-animal relationships. Perhaps we may even regard it as the archetype of animal conservation research. The Ark is mobilised (that is: endorsed as well as denounced) both in the academic literature (for instance: Norton 2015) and in the public arena (for instance: Kolbert 2013), ${ }^{1}$ but as a basic motif, the Ark is also clearly discernible in the preceding contributions to this section. My aim in this paper is to assess the strengths and weaknesses of the Ark image by commenting on these contributions (by Keulartz, Larson and Barr, Bovenkerk and Verweij, and Ramp and Bekoff), showing how this archetype may help us to understand and assess the present, although it may also become a deceptive obstacle if taken too literally, too stereotypically. My contribution builds on the work of Gaston Bachelard (1884-1962), a French philosopher of science who developed a 'psychoanalysis of scientific knowledge' to demonstrate how archetypal images may help us to structure the overload of bewildering information we are exposed to, while at the same time pointed out how easily they may become 'epistemological obstacles', preventing us from developing evidence-based and responsive views on the present (Bachelard 1938/1947; cf. Zwart 2008, p. 39 ff.). But I will also build on the work of Pierre Teilhard de Chardin (1881-1955), whom I consider a philosopher of the Anthropocene par excellence, although this is a controversial issue in itself (cf. Hamilton \& Grinevald 2015). Insofar as Teilhard may indeed be regarded as such, he was a precursor avant la lettre, because he did not actually use the term anthropocene himself. I will point out to what extent the concept of the Ark, while serving as a chronic discursive constant in describing human-animal relationships, allows us to point out the discontinuity, the unsettling newness of the anthropocenic present compared to Ark-like situations of bygone eras. Notably, in stark contrast to the traditional archetypal image (which evidently evokes the idea of an insulated, floating vessel), the anthropocenic Ark must not only assume planetary propositions, but must also remain emphatically sensitive to what is happening in the outside world; - although, in the topology of the Anthropocene, the very term 'outside' has become more or less outdated, as I will argue.

\footnotetext{
${ }^{1}$ http://animals.nationalgeographic.com/animals/photo-ark/
} 


\section{The archetypal Ark}

The biblical Story of the Ark (Genesis 6-10) is without doubt one of the most telling and provocative dramatizations of the human-animal relationship. Perhaps we may see it as the founding myth of the Anthropocene itself, projected backwards in time, with animals literally entering the age of humans. The story reflects a pastoral framing of human-animal dynamics, which should not come as a surprise, because the story was invented by a culture of livestock farmers. God is casted as an Über-livestock farmer who carefully selects his favoured samples of living beings to sacrifice the rest. The story records what we nowadays would call a bottleneck survival event. During an episode of mass extinction (due to a sudden and cataclysmic period of climate change, brought about by disruptive and unsustainable human misbehaviour), the Ark functioned as a floating, human-made zoo, a conservation device for animals in captivity (ex situ), under the leadership of someone who, unlike his contemporaries, was not only able to foresee the cataclysmic events, but also willing to heed the symptoms and to act accordingly.

From a God's eye view, moreover, even human beings are regarded as cattle in this story. The Book Genesis extrapolates the pastoral worldview even to humankind. We see God actively and consciously tending the early human populations He created, as if Genesis is actually the record of the process of human domestication, with its eventful ups and downs. The building of the Ark is preceded by a period of exponential population growth: by a massive extension of the human herd. Humankind had begun to increase in numbers, we are told (Genesis 6:1), but instead of living up to Divine expectations, most humans had become morally corrupted. The great flood represents a mythological version of a great mass extinction. It rained for forty days and nights, we are told (Genesis 7:4). But it was also an instance of Divine eugenics: only the

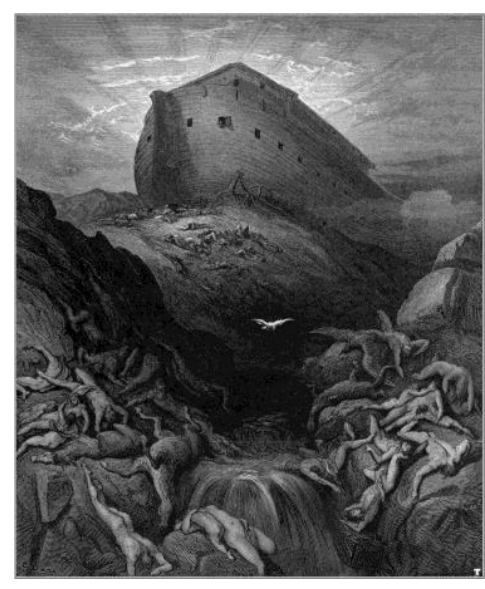
righteous survived, allowing them to initiate a second wave of population growth. This dynamics of exponential growth, sacrifice and selection, followed by subsequent waves of population growth, clearly reflects the livestock farmers' view on living conditions under domestication. Indeed, the story stages the coming-into-being of the domestication process as such.

The Ark, one could argue, really existed, namely in the form of the Neolithic village, a concept which was developed about ten millennia ago in the very region where the Ark must once have floated: in the Middle-East. During the Neolithic revolution, a new topology, a spatial reorganisation of inside - outside was introduced. Whereas wildlife (animals existing outside the 
pastoral domains or fences) continued to be exposed to survival challenges, so that many of them eventually became extinct, the agricultural or pastoral villages functioned as Arks or ecological islands, as collective immunisation devices to safeguard their domesticated inhabitants against extinction. The Ark-like village was a small insulated, humanised enclave, surrounded by a sea of wilderness, inhabited by a tiny band of human beings and their accompanying species: domesticated plants and animals which had become fully dependent on humans for their survival; and vice versa (Zwart \& Penders 2011). ${ }^{2}$

Thus, the great Deluge, as recorded in Genesis, constitutes an act of conscious selection: a human clan with desirable features is singled out, while the rest of humankind, unwilling or unable to convert to the new way of pastoral- agricultural living, finds itself decimated. Those remaining, that is: those found worthy of preservation in the struggle for survival, are allowed to re-colonize the world. Their characteristics will be transferred to future generations. Indeed, the carriers of these favoured dispositions, desirable in the eyes of God, are explicitly encouraged to reproduce as exuberantly as possible, and to become as abundant as the stars in heaven (during a night spent in the desert).

In short, the story of the Ark reflects a pastoral view on anthropogenesis, casting God as a super-shepherd in charge of human beings on their way to domestication through a series of selection bottlenecks, transforming them from inhabitants of a forest-like ecosystem called Paradise into producers of an agricultural environment of their own making: a process requiring hard labour, but also a variety of self-made artisanal tools and skills. This view is not exclusively typical for Genesis, moreover. A somewhat similar vision can be encountered in Plato's dialogue The Statesman (Подıтixós), where the ideal aristocratic ruler is presented as someone who actively tends the human herd, not only by managing, but also by systematically ameliorating the quality of the human population entrusted to his care, as if humans themselves are to be regarded as cattle; and this includes techniques for selective breeding, all for the benefit of the utopian state (Plato 1925/1995). But one could also think of survival and amelioration as a process governed by the invisible hand of evolution, a view which resonates with the subtitle of Darwin's famous book, which not only addresses the origin of species, as is suggested by the title, but also the preservation of favoured races, as indicated by the subtitle.

Gradually, the agricultural way of living (bringing together humans and animals in agricultural Arks, to safeguard their preservation), became the Common Human Pattern (Romein \& Romein 1954; cf. Zwart 2009), marginalising other ways of struggle for survival. Thus, a large

\footnotetext{
${ }^{2}$ We find this reflected in Aesop's fable of the wild and the tame donkey (Perry 183). Whereas the wild donkey initially envies his domesticated cousin, seeing him well-fed and tended, he changes his mind as soon as he sees him being put to work as a pack animal. Domestication comes with a price.
} 
part of human history can be understood as the evolution of artificial, Ark-like ecosystems involving not only human beings themselves, but also the animals and plants they selected, that is: allowed to enter the Ark (Zwart \& Penders 2011). The Neolithic Ark-like village was a clearing brought about by human domestication technologies, opening up a particular way of thinking and living. Indeed, in the course of history, human beings 'invited' a broad variety of species into their human-made environment: domesticated, semi-domesticated as well as undomesticated. But the ancient story of the Ark acquires new relevance against the backdrop of the current era, which is often referred to (also in this volume) as the 'Anthropocene'. We are facing a global environmental crisis, a mass extinction event (Kobler 2014), so that the Ark is on the move again, but this time as a symbolic type of vessel, a structure which has assumed planetary proportions. Yet, as a guiding idea, the archetypal image of the biblical Ark, if taken too literally, may also become deceptive. The Ark of the anthropocenic present clearly has to exceed the size of the agricultural or pastoral villages of the past, has to evolve into a techno-scientific and managerialregulatory network of global magnitude. Animal species worldwide are now facing an uncanny alternative: they are either allowed to enter the human Ark, the global multiple species herd, - for instance by being listed among the 7.368 or so species of vertebrates that are officially threatened with extinction, according to the 2013 IUCN Red List -, or they will vanish.

\section{Animal ethics and the anthropocene}

This diagnostics of the present, this endeavour to bring about a wholly new type of Ark, allowing us to address the challenges entailed in living under anthropocenic conditions, is acutely reflected in the contributions to this section of this volume.

The paper by Larson and Barr (this volume) for instance, focuses on the distinction between conservation in situ (in the wild) and ex situ (in captivity). The latter alternative can be regarded as the Ark-like route. Yet, as Larson and Barr argue, this distinction, although it may seem conceptually quite clear, proves increasingly difficult to uphold, especially now that we have entered the Anthropocene, the age of humans, where human impacts are omnipresent.

Conservation biologists tend to prefer in situ conservation, Larson and Barr argue, because it maintains the species in a 'natural' state rather than one 'contaminated' by human culture. But as human impacts have grown globally, it increasingly becomes necessary also to manage species under in situ circumstances. Often, endangered species have to be removed from their natural habitats (in situ) so as to be kept in captivity (ex situ), often with the idea of reintroducing them (or their descendants) into the wild at a later date. But increasingly, the intensive management of 
populations of animals in reserves (in situ) resembles the tending of animals in captivity (ex situ), while captive populations increasingly exist in 'naturalized' conditions (e.g., in zoos or botanical gardens) that are purportedly designed to be as natural as possible. In other words, the 'fingerprints' of human agency are omnipresent, while the topology of the archetypal Ark, distinctively separating inside (ex situ) from outside (in situ), has given way to a completely new situation, where the Ark no longer functions as a protective vessel or floating bubble, but increasingly as a virtual global structure which absorbs and encompasses the biosphere as such. We all live in a planetary Ark as it were, so that the in situ / ex situ dichotomy is inevitably eroding.

Jozef Keulartz (this volume) positions this debate against the backdrop of a broader philosophical diagnostics of the present. Building on Jamieson (1995) and others, Keulartz argues that, when it comes to developing an effective survival strategy for endangered animals under anthropocenic conditions, the archetypal image of the Ark may easily deceive us (Keulartz, Captivity, this volume; cf. Keulartz 2015). The image of the Ark easily becomes dysfunctional and counterproductive if taken too literally, that is: if we continue to see the Ark as an actual material zoo, as a human-made enclave of limited size: a closed animal ward as it were, where lack of occupation and activity easily gives rise to animal boredom and suffering. As a conservation device, Keulartz argues, a zoo can indeed be regarded as “a kind of Noah’s Ark” (2015, p. 337). But the Ark paradigm has "run into rough waters" or even "shipwrecked" and "no longer meets the standard". According to Keulartz, the image of the zoo as an Ark, that is: as a device for ex situ conservation, has lost its credibility and must give way to a new paradigm, which he refers to as the "integrated approach". Still, as I will argue more extensively below, while the metaphor of the Ark may indeed have run aground on the local scale, it remains a relevant concept if we try to transpose it towards the planetary scale. While the idea of the Ark as a closed ward for a limited number of endangered species may be outdated, the discarded image of the Ark emphatically resurges on a global scale, as a concept which captures the planetary situation. Increasingly, all animals (including humans) sooner or later will enter the planetary Ark.

In his contribution to an earlier section of this volume (Keulartz, Anthropocene, this volume), Keulartz further elaborates this assessment by arguing that the crisis of the zoo is symptomatic for the crisis affecting human-animal relationships during the Anthropocene as such. As wild animals are currently under increasing pressure from human activity, he argues, we inevitably have become responsible for their habitats. Moreover, living during the planet's "sixth mass extinction", care for the habitat of wild animals cannot rely merely on preservation and protection. The rate and magnitude of "defaunation" now asks for more offensive and 
interventionist strategies, such as recreation, restoration and rewilding. The unfolding crisis makes it unavoidable to replace the hands-off approach which (until recently) guided mainstream species conservation practices by a more proactive and interventionist strategy. In other words, in order to save the animal world, we have to drastically reorganize it and humanize it. We have to assume full responsibility for it. Indeed, building on the Ark-concept one could argue that we have to Ark-ize the global environment as such. In the face of mass extinction and massive ecosystem degradation, our responsibilities now inevitably assume planetary dimensions and proportions, so that the anthropocenic version of the Ark is becoming all-encompassing and omnipresent.

Similar debates can be encountered in the contribution by Bovenkerk and Verweij, who argue that the current situation requires a shift of focus from the individual to the collective dimensions of animal life. But one could even go a step further and claim that, under anthropocenic conditions, the focus must shift towards the supra-collective perspective of the planetary Ark so as to address issues of animal survival as such. Moreover, in an increasingly human-dominated world, even the kind of compassion promoted by Ramp and Bekoff (2015) may no longer be sufficient, in the sense that we should rather go for an upscaling of compassion, for something like pan-passion: a form of responsibility which aims to take the prospects for animal survival as such into account. In other words, the archetypal image of the Ark must be replaced by a symbolic, anthropocenic version, exemplifying a global strategy for coming to terms with the mass extinction threat by building an Ark which encompasses the whole animal planet, more or less. But before explaining this concept in more detail, let me first present a concise summary of the ideas of Pierre Teilhard de Chardin, one of the key preparatory thinkers (quite influential and controversial in the 1950s, 1960s and 1970s, but more or less forgotten nowadays) of the Anthropocene.

\section{The Ark, the anthropocene and the noosphere}

Teilhard's starting point is the claim that evolution has an orientation, an axis, a line of progress, a direction, namely towards increased complexity, increased self-consciousness, increased selfdirectedness (Teilhard de Chardin 1955). Living entities are increasingly able to consciously codetermine the conditions of their own evolution, and this notably applies to the most recently evolved species, namely humans. ${ }^{3}$ Teilhard sees humans beings as "evolution becoming

\footnotetext{
${ }^{3}$ Pierre Teilhard de Chardin was a Jesuit priest as well as a paleo-anthropologist who contributed to the discovery of Homo erectus fossils in China in the 1920s.
} 
conscious of itself" (p. 181). Evolution is basically a process of "sublimation" (p. 106), transposing physiology into culture, culminating in cerebralisation and, ultimately, in selfconscious self-directedness. Teilhard is well aware of the fact that in mainstream biological discourse such claims are encountered with what psychoanalysis refers to as disavowal, but for Teilhard, "sublimation" constitutes an undeniable evolutionary dynamics.

Moreover, according to Teilhard, there is something disconcerting about humans. Scientific portrayals fall short of reality. As seen by science (anatomy, physiology, genetics, molecular biology, etc.), humans are animals just like others animals, but these portraits lack an essential factor, an entire dimension. They fail to reveal how, in humans, evolution becomes an active, self-directed process, so that another world is born, the world of techno-culture. Indeed, due to global human activity, a new layer has emerged, over and above the biosphere, which Teilhard refers to as the noosphere, which literally means the "thinking layer", although besides noetic activities it also involves noetic products (technologies, devices, culture, infrastructures, and so on). In other words, the noosphere is evolving into a planetary network of advanced technologies and global communicative circuits. Humans are obviously animals, and yet we represent a discontinuity, a leap, a crisis, a metamorphosis, an awakening, giving rise to the emergence of the noosphere, the thinking layer, relentlessly transforming and absorbing the biosphere. The noosphere represents a conscious reshaping of the world, an epochal transformation affecting the entire planet.

We humans are not in charge, however, and Teilhard emphatically stresses that he does not endorse an anthropocentric view. Rather, we humans are pushed along by this development ourselves, we are subjected to a relentless process of hominization and collectivization, culminating in the emergence of a global 'We': a planetary network of thought and interaction. Indeed, Teilhard has been credited, by Garreau (2005) and others, with predicting the internet: WWW as a global noetic structure, a planetary We. For Teilhard, humans are a kind of bridge. We notice the presence of something more powerful than ourselves, he argues, pushing us forward, trawling us along: the inevitable planetisation of the noosphere. A turn of profound importance is taking place throughout the world, and we are only beginning to realise its true dimensions. We have in fact already entered a different world. "The future will decide what the best name is to describe the era we are entering", Teilhard tells us (1955, p. 214), but he clearly seems to be pointing at what we nowadays refer to as the Anthropocene. As a consequence, a sense of disquiet comes over us. We seem unable to live up to the daunting challenges and responsibilities emerging directly in front of us. The present situation is without precedent in the history of life and therefore, more than ever, we experience a fundamental existential anguish. An 
enormous responsibility is looming up in front of us and we seem to fall short in a rather dramatic way. We are waking up to the fact that the planet itself is now becoming thoroughly humanised and technified, but it is doubtful whether we will be able to manage and contain this process. It will require a process of intellectual and technological collectivisation and convergence, resulting in the emergence of a global We, empowered to initiate collective action. Somehow, our uneasiness must be transformed into active thinking, a combination of foresight and action. A terrible game is being played, and we are both the players and the cards, but only through global collaboration and scientific convergence can we hope to play a constructive rather than a disruptive role. Passive, natural, Darwinian evolution is being eclipsed by conscious transformation, an active metamorphosis of the planet. The artificial noosphere is carrying on the work of natural selection, and a computer-based, literate culture, an electronic self-consciousness, is increasingly superimposed on genetic heredity (either under domenstication or in the wild). This calls for a drastic reorganisation of scientific research itself as well, which has to be transformed into a kind of planetary organisation, allowing for global teamwork. And this even involves philosophy, which should no longer be regarded as a solitary calling, but rather as a collective endeavour, as kind of "distributed reflection", asBachelard once aptly phrased it (1940/1949, p. 2), involving multiple voices working in various places on various case studies, thereby contributing to a diagnostic of the present and prognostics of the future as a joint philosophical practice. Eventually, Teilhard remains an 'optimist', if this is still a viable term under the present circumstances. According to Teilhard, despite our failures and mistakes, we are heading towards a moment of convergence, of science, politics and art, which he refers to as the Omega Point: the end of history as we know it.

What for Teilhard still seems relatively diffuse, has now become painfully discrete, I would argue. We are witnessing a high resolution version of the global tableau drawn out somewhat sketchily by Teilhard, while excavating in the Chinese desert, several decades ago. All animals have entered the human age. And we ourselves have entered the human age as well. We have boarded the planetary Ark. The noosphere is transforming and absorbing the biosphere. Thus we are facing challenges which seem too enormous to live up to, due to lack of vision, sensitivity and coordination. In fact, we seem to have boarded a planetary ship of fools (i.e. the Ark's archetypal photographic negative or reverse image, heading for destruction) rather than an Ark. 


\section{The planetary Ark: an outline}

From a Teilhardian perspective, the archetypal Ark image can be helpful to some extent for highlighting specific features of the present, but it can also be misleading in the sense that some of its properties may prove outspokenly counterproductive. In other words, the planetary Ark must build on, but at the same time break away from the archetypal image. The most problematic feature of the archetypal Ark is that it is casted as a closed ward, a dark secluded room, screened off from reality, insensitive to what is happening outside, with no sense of direction, simply adrift. Psychoanalytically speaking, it is an instance of the mother-archetype, a replica of the motherly womb, sheltering us and saving us, protecting us from traumatic experiences, as a guardian against the frightening real, but also holding us captive and keeping us inactive. In fact, the Ark is the Biblical counterpart of Plato's famous cave, another exemplification of the mother-archetype, involving a group of humans whose legs and necks are fettered from childhood, so that they can only stare at the wall in front of them. A fire is burning higher up, at a distance behind them, and between the fire and the prisoners a low wall has been built, and behind that wall shapes of animals are carried about, as in puppet-shows, whose shadows are cast onto the wall (Plato 1935/2000, 514-515). In short, Plato's story gives us an idea of what the archetypal Ark may have looked like from the inside: a protective womb-like setting, inhabited by foetus-like passengers, chained to the uterus by umbilical cords (fetters), perfectly happy in an environment which, to outsiders, may seem claustrophobic. A facility for human husbandry, as it were, a human hatchery, where humans are kept as cattle. Interestingly, it is a kind of cinema as well, and the prisoners or passengers are watching movies featuring animals: Disney-like movies perhaps, similar to Finding Nemo, about imaginary, anthropomorphic animals: phantasmagorias whose main function seems to be an ideological one, namely to obfuscate what is really happening to animals outdoors.

But to see what reality really is like, these prisoners have to be freed from their chains by force and dragged away toward the light, the open air, so that the world of archetypal images projected on the wall $(\delta \dot{\xi} \xi \alpha)$ is replaced by true knowledge ( $\dot{\boldsymbol{\varepsilon}} \pi \iota \tau \dot{\eta} \mu \eta)$. But to achieve this, the prisoners have to be educated (literally: guided upward): a process of enlightenment and liberation, but also a traumatic experience, similar to the trauma of birth, a painful intellectual awakening.

Humankind currently still has to go through this experience, so it seems. The extinction catastrophe, the massive loss of biodiversity is still met with disavowal and sheer indifference. The emerging crisis is a traumatic experience no doubt, and to really expose ourselves to it, we 
must leave the archetypal Ark behind and wholeheartedly enter the planetary, anthropocenic version. Science is basically "iconoclastic", Bachelard argues (1938/1947, p. 77), and the archetypal image of the Ark must be demolished and replaced by a completely different type of vessel: open to the world, informed by research; a kind of global observatory, in short. The anthropocenic Ark is not constructed out of wood, but rather consists of symbolical, noetic materials: scientific findings, responsive deliberations, conservation policies. In order to come to terms with the present, the concept of the Ark has to be transferred from the imaginary realm (the archetypal Gestalt of the Ark as a secluded ward) into the symbolical realm (the planetary, anthropocenic Ark, informed by research-based diagnostics and quantified prognostics). This Ark is no longer steered by one individual, moreover, a Noah-like guide or super-sailor. Rather, the planetary Ark is staffed by a kind of global, collective consciousness, combining multidisciplinary data with a readiness to act.

This also has implications for the role and place of philosophers, who have to leave their traditional Arks, their secluded wards, their introvert libraries, in order to participate in what Bachelard referred to as distributed reflection. Thus, a philosophical diagnostics of the present becomes a joint endeavour to which multiple voices may contribute, via a plethora of philosophical case studies, such as the ones brought together in this section, concerning in situ and ex situ conservation and zoos as conservation devices. Thus philosophers may contribute to a growing convergence of thought and action. A planetary Ark will allow humans to assume responsibility for the present situation, not because their track record of former achievements is so promising, but rather because, in the absence of divine intervention, the global We is the only agent available to play this role. Should we fail to achieve this, the planetary fauna will continue to float in the direction of the coming deluge, and the global Ark will definitely revert into a wandering ship of fools.

\section{References}

Bachelard G. (1940/1949) La Philosophie du non. Essai d'une philosophie du nouvel esprit scientifique. Paris : Presses Universitaires de France.

Bachelard G. (1938/1947) La formation de l'esprit scientifique. Contribution à une psychanalyse de la connaissance objective. Paris: Vrin 
Bovenkerk B.,Verweij B (this volume) Collective dimensions in animal ethics. In: Animal Ethics in the Age of Humans. Springer.

Garreau J. (2005) Radical evolution: the promise and peril of enhancing our minds, our bodies and what it means to be human. New York: Broadway Books.

Hamilton C., Grinevald J. (2015) was the anthropocene anticipated. The Anthropocene Review 2 (1): 59-72.

Jamieson, D. (1995). 'Zoos revisited.' In B. Norton, M. Hutchins, E. Stevens, \& T. Maple (Eds.), Ethics on the Ark (pp. 52-66). Washington: Smithsonian Institution Press.

Keulartz J. (2015) Captivity for Conservation? Zoos at a Crossroads. Journal of Agricultural and Environmental Ethics 28:335-351.

Keulartz J. (this volume) Towards an Animal Ethics for the Anthropocene. In: Animal Ethics in the Age of Humans. Springer.

Kolbert E. (2013) Building the Ark. National geographic. October 2013.

Kolbert E. (2014) The Sixth Extinction: An Unnatural History. New York: Holt

Larson B., Barr S. (this volume) The flights of the Monarch butterfly: Between in situ and ex situ conservation. In: Animal Ethics in the Age of Humans. Springer.

Monastersky, R. 2015. The human age. Nature 519: 144-147.

Norton B., Hutchins M., Stevens E., \& Maple T. (Eds.), Ethics on the Ark. Washington: Smithsonian Institution Press.

Plato (1925/1995) The statesman, Philebus, Ion. Plato VIII [Loeb]. Cambridge: Harvard University Press.

Plato (1935/2000) Republic VI-X. Plato VI [Loeb]. Cambridge: Harvard University Press Ramp D, Bekoff M. (2015) Compassion as a Practical and evolved Ethic for Conservation.

BioScience 65 (3): 323-327.

Romein, J., \& Romein-Verschoor, A. (1954). Aera van Europa. Leiden: Brill.

Teilhard de Chardin P. (1955) The Phenomenon of Man. New York: Harper

Zwart H. (2008) Understanding nature: Case studies in comparative epistemology. Dordrecht: Springer

Zwart H. (2009) Biotechnology and naturalness in the genomics era: plotting a timetable for the biotechnology debate. Journal of Agricultural and Environmental Ethics, 22, 505-529.

Zwart H., Penders B (2011) Genomics and the Ark. An ecocentric perspective on human history. Perspectives in Biology and Medicine 54 (2):217-31. 